\title{
Biosynthesis of zinc oxide nanoparticle: a review on greener approach
}

\begin{abstract}
Past few decades application of nanoparticle in the different fields like biomedical, cosmetic, food and many more has gained much importance globally because of its size and unique properties, hence it become an important field among the researchers. Recently in nanotechnology research, synthesis of nanoparticle from green chemistry pathways has been preferred due to its natural biological reduction property which reduces the utilization and exposure of toxic chemical to the environment when compare to physical and chemical methods. Among the different inorganic nanoparticles, zinc oxide nanoparticle attracts more attention due to its, large bandwidth, high excitation binding energy, simplicity, easy fabrication, biosafe, non-toxic, biocompatible, eco and environmental friendly. Zinc oxide nanoparticle is readily soluble in biological fluids and tends to aggregate easily under different physiological condition. But physicochemical properties of the nanoparticle have an impact in the bioavailability. This review was to make an attempt to summarize and conclude green synthesis of zinc oxide nanoparticle and its pharmacokinetic properties.
\end{abstract}

Keywords: nanoparticle, zinc oxide, non-toxic, bioavailability, pharmacokinetic properties
Volume 5 Issue 3 - 2018

\author{
Umamaheswari A, Lakshmana Prabu S, \\ Puratchikody A \\ Department of Pharmaceutical Technology, University College \\ of Engineering, India
}

\section{Correspondence: Umamaheswari A, Department of} Pharmaceutical Technology, University College of Engineering, BIT Campus, Anna University, Tiruchirappalli-620024,Tamilnadu, India, Email umapharmaaut@gmail.com

Received: May 31, 2018 | Published: June 12, 2018

\section{Introduction}

In last few decades the revolution of nanotechnology exhibit significant and commercial application in different fields like engineering, environmental science, agriculture, medicine, electrical and electronics, pharmaceutical, biological, biotechnology, mineral nutrition, food processing, reproduction, pharmacology applications and many more. ${ }^{1}$ The significant and increased commercial applications are owing to its nanoscale dimension, large surface area to volume ratio, unique and potential properties like electronic, magnetic, mechanical, non-linear optical performance, thermal conductivity, enhanced catalytic reactivity and chemical steadiness. ${ }^{2-4}$ Real research and development in nanotechnology is concern with making modification in its atomic, molecular and supra-molecular levels to improve its physicochemical properties to produce desired effect. $^{1}$

Inorganic nanoparticles are made by combining organic materials with inorganic materials which forms hybrids and has unique properties. ${ }^{5}$ Different inorganic nanoparticles like quantum dots, magnetic, silver, gold, $\mathrm{SiO}_{2}, \mathrm{TiO}_{2}, \mathrm{CuO}$ and $\mathrm{ZnO}$ nanoparticles have been synthesized and utilized in various fields. Zinc oxide nanoparticle has large bandwidth and high excitation binding energy, ${ }^{6}$ made researchers to explore its potential application in different fields. Among the different inorganic nanoparticles, $\mathrm{ZnO}$ nanoparticle is the third highest nanoparticle produced globally and utilized in different fields. ${ }^{7}$

\section{Synthesis of nanoparticle}

Processes for the preparation of inorganic nanoparticle by different physical and chemical method are:

a. Vapor transport and condensation

b. Amorphous crystallization

c. Physical fragmentation

d. Pulsed laser deposition
e. Molecular beam epitaxy
f. Thermal evaporation and decomposition
g. Chemical micro emulsion
h. Wet chemical
i. Spray pyrolysis
j. Electrode-position
k. Direct precipitation
1. Homogeneous precipitation
m. Microwave assisted combustion
n. Solvothermal method
o. Sonochemical method
p. Reverse micelles
q. Sol gel method
r. Microwave irradiation
s. Reaction of zinc with alcohol
t. Hydrothermal synthesis
u. Micro emulsion synthesis
v. Spray drying ${ }^{6,8}$

However, the major drawback of the physical method is the involvement of high pressure and temperature whereas in the chemical method is the utilization of toxic chemicals, ${ }^{9}$ also capping and stabilizing agents are additionally needed. ${ }^{6}$

\section{Green synthesis}

Hence, researchers focus towards the green synthesis of nanoparticle from microorganisms like bacteria, algae, fungi, yeast and different plant parts like leaves, fruits, seeds, roots and stems for various applications. ${ }^{6,8,10-13}$ Green synthesis of nanoparticle from plants are more stable, varied shape and size when compare to nanoparticle synthesized from other organisms. ${ }^{14}$ Green synthesis approach shows more catalytic activity and limits the exposure, utilization of toxic and 
expensive chemicals; which can help to protect the environment from chemical toxicity and hazardous.

\section{Synthesis of zinc oxide nanoparticle}

Desired quantity zinc oxide or zinc nitrate or zinc acetate or zinc sulfate is dissolved in distilled water. To the zinc solution, defined volume of plant extract is added and mixed well in a magnetic stirrer. To adjust the $\mathrm{pH}$ of the above mixture to $\mathrm{pH} 12, \mathrm{NaOH}$ solution is added drop by drop with continuous stirring and kept for $1 \mathrm{hr}$ as incubation time. The color of the reaction mixture is changed after $1 \mathrm{~h}$ of incubation time. Formation of nanoparticle is confirmed in UV spectroscopy based on its surface plasmon resonance (SPR) effect. Formed white crystalline precipitate of Zinc oxide nanoparticle is separated from the reaction solution by centrifugation and dried in a hot air oven operating at $60-80^{\circ} \mathrm{C}$ for $2 \mathrm{hr} . .^{15}$

The chemical reaction process for the formation of zinc oxide nanoparticle from zinc acetate is shown in the following chemical equation $^{15}$.

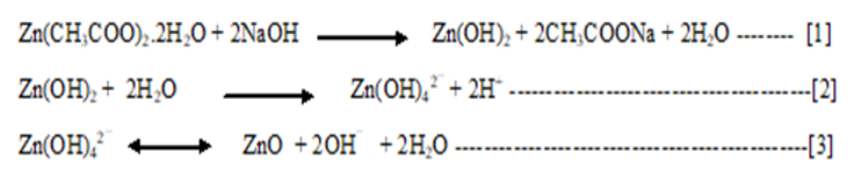

Plants secrete phytoconstituents like amino acids, vitamins, terpenoids, alkaloids, polyphenol and polysaccharides which can acts as reducing agent as well as capping or stabilizing agent. Also these phytoconstituents reduce metal ions or metal oxides into zero valence metal nanoparticles. Hence, no capping or stabilizing agents are needed in this green approach of nanoparticle synthesis. ${ }^{6,16}$ This green synthesis approach is easy fabrication, cost effective, non-toxic, biocompatible, environment friendly and safe. Also US Food and Drug Administration (US FDA) enlisted $\mathrm{ZnO}$ with other four zinc compounds are generally recognized as safe (GRAS) material. ${ }^{17}$ In general for the $\mathrm{ZnO}$ nanoparticle synthesis zinc oxide or zinc nitrate or zinc acetate or zinc sulfate are used. Different factors like temperature, $\mathrm{pH}$, time and concentration of extract have important role in obtaining desired size and shape of the nanoparticle. ${ }^{18}$ Formation $\mathrm{ZnO}$ Nanoparticle is confirmed in UV spectroscopy based on its surface plasmon resonance (SPR) effect. ${ }^{8}$ Different morphologies of $\mathrm{ZnO}$ Nanoparticles are nanoflower, nanoflake, nanorods, nanowire and nanobelt. ${ }^{6}$ Synthesis of zinc oxide nanoparticle from different natural plant source ${ }^{6}$ is shown in Figure 1 and the steps for the preparation of zinc oxide nanoparticle, ${ }^{19}$ are shown in Figure 2.

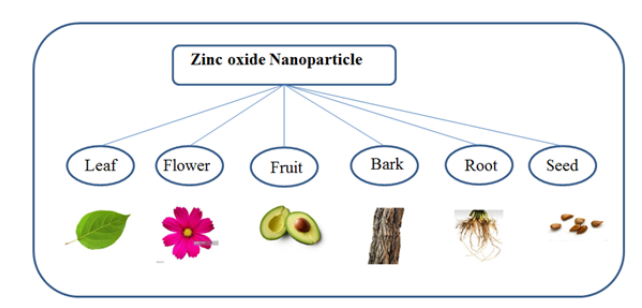

Figure I Synthesis of zinc oxide nanoparticle from different natural plant source.

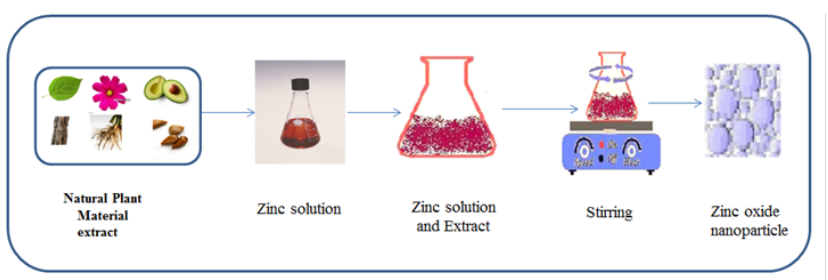

Figure 2 Steps for the preparation of zinc oxide nanoparticle.

\section{Nanoparticle characterization}

Synthesized nanoparticles are characterized for its properties by

a. Fourier transform infra-red spectroscopy (FT-IR)-Assess the binding properties of nanoparticles.

b. Scanning electron microscopy (SEM)-Assess the morphology and visualize shape and size of nanoparticle.

c. X-ray diffractometer (XRD)-Spectra provides an insight about the crystallinity of nanoparticle.

d. Atomic Force Microscopy-Assess the topography, rough-ness of nanoparticles. ${ }^{8,20}$

\section{Pharmacokinetic properties}

\section{Absorption}

Zinc oxide nanoparticles are less stable and readily soluble in biological fluids and subsequently release zinc ions. ${ }^{21,22}$ On oral administration first pass effect, gastrointestinal barrier, liver and gut wall function decreases the bioavailability of $\mathrm{ZnO}$ nanoparticles; whereas on intravenous administration shows $100 \%$ bioavailability. ${ }^{23}$ Different factors like $\mathrm{pH}$, particle size, concentration and presence or absence of organic compounds influence the solubility of $\mathrm{ZnO}$ nanoparticles. However negative charge particles are absorbed more when compare to the positive charge particles. ${ }^{24}$ Dissolution, absorption and distribution of $\mathrm{ZnO}$ nanoparticles are depend upon the exposure dose amount and does not depend upon the particle size of the nanoparticle. ${ }^{23}$

\section{Distribution}

On oral administration, zinc oxide nanoparticles are distributed in kidney, liver and spleen whereas on intraperitoneal administration zinc oxide nanoparticles are distributed in lungs, kidney, spleen, heart and liver. ${ }^{25,26}$ Kidneys and liver is the common target organ on both administrations. Distribution of zinc in the organs are depends upon the type of experimental animals, route of exposure and physicochemical properties of the nanoparticles.

\section{Excretion}

Metabolites and wastes from $\mathrm{ZnO}$ nanoparticles have less than $6 \mathrm{~nm}$ in hydrodynamic diameter are eliminated through urine by glomerular filtration, ${ }^{27,28}$ both absorbed and nonabsorbed entities are excreted through fecal, whereas metabolites are excreted via bile. Exposure route and physicochemical properties has an important role in the excretion of the $\mathrm{ZnO}$ nanoparticles; but biliary and fecal excretion are having major role in the elimination of the nanoparticle irrespective of its particle size, surface charge and exposure routes. Excretion kinetic of the nanoparticle is depends upon the particle size rather than the surface charge of the particle..$^{24,25}$ 


\section{Protein interaction}

When nanoparticles contact with biological fluid in systemic circulation, rapid interaction occurs leads to adsorption of protein on the nanoparticle surface. Adsorption of the protein on the nanoparticle surface is highly depends on the surface charge and particle size of the nanoparticle. Plasma protein like fibrinogen, lipoprotein, albumin and immunoglobulins are utilized to assess the binding, adsorption and subsequent protein structure changes due to nanoparticle protein interaction. Also plasma protein plays a crucial role in deposition, disposition and transportation, ${ }^{29-32}$ (Figure 3).

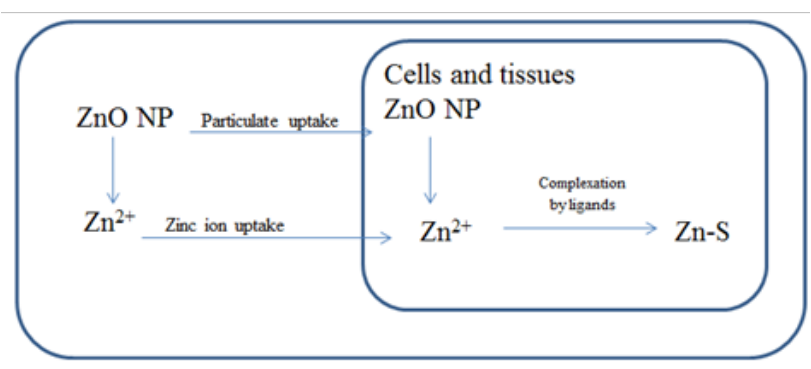

Figure 3 Distribution of $\mathrm{Zn}^{2+}$ in the biological system

\section{Applications}

Various green synthesized $\mathrm{ZnO}$ nanoparticle applications are shown in Table 1.

Table I Application of green synthesized $\mathrm{ZnO}$ nanoparticle

\begin{tabular}{lll}
\hline S. No & Name of the plant (Parts) & Application \\
\hline 1 & Trifolium pratense (flower) & antibacterial activity ${ }^{33}$ \\
2 & Catharanthus roseus (leaf) & Antibacterial activity \\
3 & Murraya koenigii (seed) & Antimicrobial activity ${ }^{35}$ \\
4 & $\begin{array}{l}\text { Nyctanthes arbortristis } \\
\text { (flower) }\end{array}$ & Anti-fungal $^{18}$ \\
5 & Passiflora caerulea (Leaf) & Urinary tract infection $^{8}$ \\
6 & Hibiscus subdariffa (leaf) & Anti diabetic \\
7 & Polygala tenuifolia (root) & Anti-inflammatory $^{37}$ \\
8 & Eucalyptus globulus (leaf) & Antioxidant $^{38}$ \\
\hline
\end{tabular}

\section{Conclusion}

Green synthesis of zinc nanoparticle has gained much importance recently due to its biocompatible and eco-friendly nature. Phytoconstituents secreted from natural sources act as both reducing as well as stabilizing agent. This green synthesis approach produce maximal and narrow size range nanoparticle between 1 and $100 \mathrm{~nm}$ which greatly reduce the utilization of other physical and chemical methods of synthesis. Zinc as ion have significant role in functional and integrity of cell structure. Further extensive research need to be performed to establish the procedure from bench to large scale production and its utilization in different fields commercially. Also the zinc oxide nanoparticles pharmacokinetic and bioavailability are still need to be performed to understand and establish the exact mechanism in human being.

\section{Acknowledgements}

None.

\section{Conflict of interest}

The author declares no conflict of interest.

\section{References}

1. Swain PS, Rao SBN, Rajendran D, et al. Nano zinc, an alternative to conventional zinc as animal feed supplement: A review. Animal Nutrition. 2016;2(3):134-141.

2. Khan ST, Musarrat J, Al-Khedhairy AA. Colloids and surfaces B: biointerfaces countering drug resistance, infectious diseases, and sepsis using metal and metal oxides nanoparticles: current status. Colloids Surf B Biointerfaces. 2016;146:70-83.

3. Sathishkumar M, Sneha K, Won SW, et al. Cinnamon zeylanicum bark extract and powder mediated green synthesis of nano-crystalline silver particles and its bactericidal activity. Colloids and Surfaces $B$ Biointerfaces. 2009;73(2):332-338.

4. Rajendran SP, Sengodan K. Synthesis and Characterization of Zinc Oxide and Iron Oxide Nanoparticles Using Sesbania grandiflora Leaf Extract as Reducing Agent. Journal of Nanoscience. 2017; Article ID 8348507:7.

5. Lakshmana Prabu S, Suriya Prakash TNK, Thirumurugan R. Medicated nanoparticle for gene delivery. In: Sabyasachi Maiti, Kalyar Kumar Sen, editors. Advanced technology for delivering therapeutics. InTech Publication, Croatia, 2017;13-29.

6. Agarwal H, Venkat Kumar S, Rajeshkumar S. A review on green synthesis of zinc oxide nanoparticles-An eco-friendly approach. Resource-Efficient Technologies. 2017;3(4):406-413.

7. Piccinno F, Gottschalk F, Seeger S, et al. Industrial production quantities and uses of ten engineered nanomaterials for Europe and the world. Journal of Nanoparticle Research. 2012;14:1109.

8. Santhoshkumar J, Venkat Kumar S, Rajeshkumar S. Synthesis of zinc oxide nanoparticles using plant leaf extract against urinary tract infection pathogen. Resource-Efficient Technologies. 2017;3(4):459-465.

9. Sabir S, Arshad M, Chaudhari SK. Zinc oxide nanoparticles for revolutionizing agriculture: synthesis and applications. The Scientific World Journal. 2014;Article ID 925494:8.

10. Ramesh M, Anbuvannan M, Viruthagiri G. Green synthesis of $\mathrm{ZnO}$ nanopar- ticles using Solanum nigrum leaf extract and their antibacterial activity. Spectrochim Acta A Mol Biomol Spectrosc. 2015;136(Pt B):864-870

11. Rajiv P, Rajeshwari S, Venckatesh R. Bio-Fabrication of zinc oxide nanoparti-cles using leaf extract of Parthenium hysterophorus L. and its size-dependent antifungal activity against plant fungal pathogens. Spectrochim Acta A Mol Biomol Spectrosc. 2013;112:384-387.

12. Anbukkarasi V, Srinivasan R, Elangovan N. Antimicrobial activity of green synthesized zinc oxide nanoparticles from Emblica officinalis, Int J Pharm Sci Rev Res. 2015;33(2):110-115.

13. Rajeshkumar S. Anticancer activity of eco-friendly gold nanoparticles against lung and liver cancer cells. Journal of Genetic Engineering and Biotechnology. 2016;14(1):195-202.

14. Qu J, Yuan X, Wang X, et al. Zinc accumulation and synthesis of $\mathrm{ZnO}$ nanoparticles using Physalis alkekengi L. Environ Pollut. 2011;159(7):1783-1788.

15. Osman DAM, Mustafa MA. Synthesis and Characterization of Zinc Oxide Nanoparticles using Zinc Acetate Dihydrate and Sodium Hydroxide. Journal of Nanoscience and Nanoengineering. 2015;1(4): $248-251$.

16. Heinlaan M, Ivask A, Blinova I, et al. Toxicity of nano- sized and bulk $\mathrm{ZnO}, \mathrm{CuO}$ and $\mathrm{TiO}_{2}$ to bacteria Vibrio fischeri and crustaceans Daphnia 
magna and Thamnocephalus platyurus. Chemosphere. 2008;71(7):13081316.

17. Jamdagni P, Khatri P, Rana JS. Green synthesis of zinc oxide nanoparticles using flower extract of Nyctanthes arbor-tristis and their antifungal activity. Journal of King Saud University-Science. 2018;30(2):168-175.

18. Ochieng PE, Iwuoha E, Michira I, et al. Green route synthesis and characterization of $\mathrm{ZnO}$ nanoparticles using Spathodea campanulata. International Journal of BioChemiPhysics. 2015;23:53-61.

19. Ingale AG, Chaudhari AN. Biogenic Synthesis of Nanoparticles and Potential Applications: An Eco-Friendly Approach. J Nanomed Nanotechol. 2013;4:165.

20. Mohan AC, Renjanadevi B. Preparation of Zinc Oxide Nanoparticles and its Characterization Using Scanning Electron Microscopy (SEM) and X-Ray Diffraction (XRD). Procedia Technology. 2016; 24:761-766.

21. Li M, Lin D, Zhu L. Effects of water chemistry on the dissolution of $\mathrm{ZnO}$ nanoparticles and their toxicity to Escherichia coli. Environ Pollut. 2013;173:97-102.

22. Mudunkotuwa IA, Rupasinghe $\mathrm{T}$, Wu CM, et al. Dissolution of $\mathrm{ZnO}$ nanoparticles at circumneutral $\mathrm{pH}$ : a study of size effects in the presence and absence of citric acid. Langmuir. 2012;28(1):396-403.

23. Choi SJ, Choy JH. Biokinetics of zinc oxide nanoparticles: toxicokinetics, biological fates and protein interaction. Int J Nanomedicine. 2014;9(Suppl 2):261-269.

24. Paek HJ, Lee YJ, Chung HE, et al. Modulation of the pharmacokinetics of zinc oxide nanoparticles and their fates in vivo. Nanoscale. 2013;5(23):11416-11427.

25. Baek M, Chung HE, Yu J, et al. Pharmacokinetics, tissue distribu $\neg$ tion, and excretion of zinc oxide nanoparticles. Int $J$ Nanomedicine. 2012;7:3081-3097.

26. Li CH, Shen CC, Cheng YW, et al. Organ biodistribution, clearance, and genotoxicity of orally administered zinc oxide nanoparticles in mice. Nanotoxicology. 2012;6(7):746-756.

27. Deen WM, Lazzara MJ, Myers BD. Structural determinants of glomerular permeability. Am J Physiol Renal Physiol. 2001; 281(4):F579-F596.

28. Ohlson M, Sorensson J, Haraldsson B. A gel-membrane model of glomerular charge and size selectivity in series. Am J Physiol Renal Physiol. 2001;280(3):396-405.

29. Bhogale A, Patel N, Sarpotdar P, et al. Systematic investigation on the interaction of bovine serum albumin with $\mathrm{ZnO}$ nanoparticles using fluorescence spectroscopy. Colloids Surf B Biointerfaces. 2013;102:257264.

30. Xiao J, Wang F, Liu J, et al. Effect of ZnO\#ZnS QDs heterojunctures on the stilbenes-plasma proteins interactions. Mol Biosyst. 2011;7(8):24522458 .

31. Deng ZJ, Mortimer G, Schiller T, et al. Differential plasma protein binding to metal oxide nanoparticles. Nanotechnology. 2009;20(45):455101.

32. Dutta D, Sundaram S, Teeguarden J, et al. Adsorbed proteins influence the biological activity and molecular targeting of nanomaterials. Toxicol Sci. 2007;100(1):303-315.

33. Dobrucka R, Dugaszewska J. Biosynthesis and antibacterial activity of $\mathrm{ZnO}$ nanoparticles using Trifolium pratense flower extract. Saudi J Biol Sci. 2016;23(4):517-523.

34. Bhumi G, Savithramma N. Biological Synthesis of Zinc oxide Nanoparticles from Catharanthus roseus (1.) G. Don. Leaf extract and validation for antibacterial activity. International Journal of Drug Development and Research. 2014;6(1):208-214.

35. Sundaraselvan G, Quine SD. Green synthesis of zinc oxide nanoparticle using seed extract of Murraya Koenigii and their antimicrobial activity against some human pathogens. Journal of nanoscience and technology. 2017;3(4):289-292.

36. Bala N, Saha S, Chakraborty M, et al. Green synthesis of zinc oxide nanoparticles using Hibiscus subdariffa leaf extract: effect of temperature on synthesis, anti-bacterial activity and anti-diabetic activity. RSC Advances. 2015;5(7):4993-5003.

37. Nagajyothi PC, Cha SJ, Yang IJ, et al. Antioxidant and anti-inflammatory activities of zinc oxide nanoparticles synthesized using Polygala tenuifolia root extract. J Photochem Photobiol B. 2015;146:10-17.

38. Balaji S, Kuma MB. Facile green synthesis of zinc oxide nanoparticles by Eucalyptus globulus and their photocatalytic and antioxidant activity. Advanced Powder Technology. 2017;28(3):785-797. 